\title{
Comparison of Cell-Mediated Immunity Induced by Three Commercial Single-Dose Mycoplasma hyopneumoniae Bacterins in Pigs
}

\author{
Hwi Won SEO ${ }^{1}$, Kiwon $\mathrm{HAN}^{1}$, Yeonsu $\mathrm{OH}^{1)}$, Changhoon PARK ${ }^{1)}$, Eun Jeong $\mathrm{CHOO}^{2)}$, Sung-Hoon $\mathrm{KIM}^{2}$, \\ Bog-Hieu LEE ${ }^{3)}$ and Chanhee $\mathrm{CHAE}^{1) *}$ \\ ${ }^{1)}$ Department of Veterinary Pathology, College of Veterinary Medicine, Seoul National University, 599 Gwanak-ro, Gwanak-gu, Seoul, \\ Republic of Korea \\ ${ }^{2)}$ College of Oriental Medicine, Kyunghee University, 1 Hoegi-dong, Dongdaemun-ku, Seoul 130-701, Republic of Korea \\ 3) Department of Food and Nutrition, Chung-Ang University, 72-1 Nae-Ri, Daedeok-Myeon, Gyeonggi-Do 456-756, Republic of Korea
}

(Received 2 July 2012/Accepted 28 September 2012/Published online in J-STAGE 12 October 2012)

ABSTRACT. This study was to compare the degree of cell-mediated immunity induced by three commercial Mycoplasma hyopneumoniae bacterins using interferon- $\gamma$ (IFN- $\gamma$ ) measurements, lymphocyte stimulation assays and delayed-type hypersensitivity tests. Serum IFN- $\gamma$ levels were significantly elevated in all four vaccinated pig groups at 21 days post-vaccination $(P<0.05)$. Lymphocytes isolated 21 days postvaccination exhibited significantly more proliferation in response to $M$. hyopneumoniae than lymphocytes isolated 0 day pre-vaccination $(P<0.05)$. Following intradermal injection of M. hyopneumoniae antigen at 14, 21 or 28 days post-vaccination, all pigs in the four vaccinated groups displayed skin reactions characterized by circumscribed, often erythematous nodules. Taken together, these demonstrate that all three commercial single-dose M. hyopneumoniae bacterins used in this study induce varying degrees of cell-mediated immunity. KEY WORDS: cell-mediated immunity, Mycoplasma hyopneumoniae, vaccination.

doi: 10.1292/jvms.12-0292; J. Vet. Med. Sci. 75(2): 245-247, 2013

Mycoplasma hyopneumoniae is a causative agent of swine mycoplasmal pneumonia, a disease that is widespread and causes economic losses in the swine industry through stunted growth and susceptibility of the swine to infection by other pathogenic organisms [14]. M. hyopneumoniae is predominantly transmitted through nose-to-nose animal contact; less frequently, aerosolization of the agent maintains horizontal spread from infected to naive pigs of the same age, or vertical transmission from sows to their offspring [14]. To combat vertical and horizontal transmission, it has been suggested that vaccination of suckling piglets before $M$. hyopneumoniae infection during the first week of life may assist $M$. hyopneumoniae control. Since a correlation between cell-mediated immunity and protection from mycoplasmal disease has been reported $[4,16]$, cellmediated immunity is important for control of mycoplasmal pneumonia in pigs. Single-dose $M$. hyopneumoniae bacterin was first introduced in 1998, and since then, several commercial single-dose $M$. hyopneumoniae bacterins have been routinely used in swine farms. Although one previous study reported the induction of cell-mediated immunity by two single-dose commercial M. hyopneumoniae bacterins [15], however, no one has compared induction of cell-mediated immunity by three commercial single-dose M. hyopneumoniae bacterins and by the same $M$. hyopneumoniae bacterin at different age. The purpose of the present study was to investigate the degree of cell-mediated immunity induced

*Correspondence to: Chae, C., Department of Veterinary Pathology, College of Veterinary Medicine, Seoul National University, 599 Gwanak-ro, Gwanak-gu, Seoul, Republic of Korea. e-mail: swine@snu.ac.kr

C2013 The Japanese Society of Veterinary Science by three commercial single-dose $M$. hyopneumoniae bacterins using interferon- $\gamma$ (IFN- $\gamma$ ) measurements, lymphocyte stimulation assays and delayed-type hypersensitivity (DTH) tests in pigs at different ages.

Fifty colostrum-fed, cross-bred conventional pigs, farrowed from unvaccinated (for M. hyopneumoniae) and seronegative gilts, were purchased from a commercial farm. All pigs tested negative for porcine circovirus type 2 (PCV2), porcine reproductive and respiratory syndrome virus and $M$. hyopneumoniae by routine serological testing. Individual pigs were uniquely identified from seven days of age by single ear notches. These pigs were randomly sorted into five groups of ten pigs each.

Three commercial single-dose $M$. hyopneumoniae bacterins were investigated in this study. M. hyopneumoniae bacterin A (2.0 ml; Respisure One, Pfizer Animal Health, New York, NY, U.S.A.) was administered to the pigs of groups T01 and T02 at 7 or 21 days of age, respectively. At 21 days of age, the pigs of groups T03 and T04 were vaccinated with $M$. hyopneumoniae bacterin B $(2.0 \mathrm{~m} l$; Mhyo, Boehringer Ingelheim Animal Health, St. Joseph, MO, U.S.A.) or bacterin C (1.0 ml; Mycoflex, Boehringer Ingelheim Animal Health), respectively. Pigs serving as the negative control (group T05) remained unvaccinated.

A minimum of $10 \mathrm{~m} l$ whole blood was collected for IFN- $\gamma$ measurement and lymphocyte stimulation assay at 0 day pre-vaccination and 21 days post-vaccination. Porcine-specific IFN- $\gamma$ levels in sera were measured with an enzyme-linked immunosorbent assay (Pierce Biotechnology, Inc., Rockford, IL, U.S.A.) according to the manufacturer's instructions. Antigen for lymphocyte stimulation was prepared from M. hyopneumoniae (ATCC 25934), and concentration was adjusted to $4 \mathrm{mg} / \mathrm{ml}$. The lymphocyte 
stimulation assay was performed as previously described [2].

DTH test was performed on 50 piglets from 5 groups at 14,21 and 28 days post-vaccination as previously described [2]. Piglets were injected intradermally on the left inguinal area with $0.1 \mathrm{~m} l$ of a solution containing $M$. hyopneumoniae antigen (ATCC 25934; $300 \mu \mathrm{g} / \mathrm{ml}$ ). Thirty-six hours after antigen injection, swollen erythema of the injection site was measured as previously described [12]. The longest and midpoint orthogonal diameters of the erythema were measured with engineering automated calipers and used to calculate the area of the erythema.

For single comparisons, ANOVA with post-hoc Tukey's test was applied to the primary variables (IFN- $\gamma$, lymphocyte stimulation assay and DTH test) among groups. Pearson correlation analysis was used to assess correlations of the primary variables among groups. For all statistical tests, $P<0.05$ was considered statistically significant.

Serum IFN- $\gamma$ levels were not detected in all pigs from 5 groups at 0 day pre-vaccination but significantly elevated in all four vaccinated groups at 21 days post-vaccination, although pigs from group T01 exhibited significantly higher serum IFN- $\gamma$ levels than pigs from other 4 groups (T02, T03, T04 and T5; $P<0.05$; Fig. 1). Lymphocytes isolated from pigs at 21 days post-vaccination manifested significantly more proliferation in response to $M$. hyopneumoniae than lymphocytes isolated at 0 day pre-vaccination $(P<0.05$; Fig. $2)$. Higher amounts of proliferation were observed in the lymphocytes of pigs from group T01 in response to $M$. hyopneumoniae than lymphocytes from the other three vaccinated groups (T02, T03 and T04; $P<0.05$; Fig. 2). Additionally, M. hyopneumoniae-specific lymphocyte proliferation in pigs from group T01 strongly and significantly correlated with serum IFN- $\gamma$ levels $\left(r^{2}=0.775, P<0.008\right)$. Following intradermal injection of $M$. hyopneumoniae antigen at 14,21 , or 28 days post-vaccination, all pigs in the four vaccinated groups (T01, T02, T03 and T04) displayed skin reactions characterized by circumscribed, often erythematous nodules 24 to $48 \mathrm{hr}$ later. Pigs in group T01 (14.25 \pm 3.12$)$ had significantly greater DTH response size than pigs in other vaccinated groups $(10.17 \pm 2.38$ for $\mathrm{T} 02 ; 9.6 \pm 2.52$ for $\mathrm{T} 03$; $9.8 \pm 3.18$ for T04; $P<0.05)$. The nodules regressed slowly after $48 \mathrm{hr}$, leaving no scar or skin reaction. The scores from this DTH test in three vaccinated groups correlated strongly and significantly with serum IFN- $\gamma$ levels: pigs in groups T01 $\left(r^{2}=0.757, P<0.011\right)$, T02 $\left(r^{2}=0.764, P<0.010\right)$ and T03 $\left(r^{2}=0.688, P<0.028\right)$.

The present study has demonstrated that three commercial single-dose $M$. hyopneumoniae bacterins induced various degrees of cellular immune responses in pigs, as assayed by IFN- $\gamma$ measurements, lymphocyte stimulation assays and DTH testing. Interestingly, pigs vaccinated with $M$. hyopneumoniae bacterin A at 7 days of age displayed stronger cellular immune responses than the other pigs vaccinated with $M$. hyopneumoniae bacterin A, B or $\mathrm{C}$ at 21 days of age on the basis of IFN- $\gamma$ measurements and lymphocyte stimulation assays. Although we have no clear explanation for this observation, we assume that strong immunity can be induced before the pigs become infected, when fewer

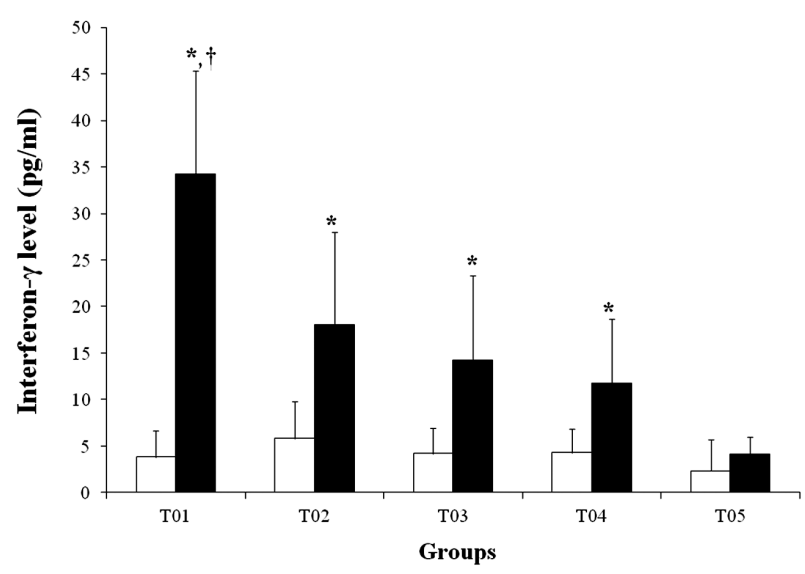

Fig. 1. Interferon- $\gamma$ levels measured from blood samples collected from pigs at 0 day pre-vaccination $(\square)$ and 21 days post-vaccination (ם). Variation is expressed as standard deviation; *Significant difference between 0 day pre-vaccination and 21 days post-vaccination $(P<0.05)$; $\uparrow$ Significant difference among all groups $(P<0.05)$.

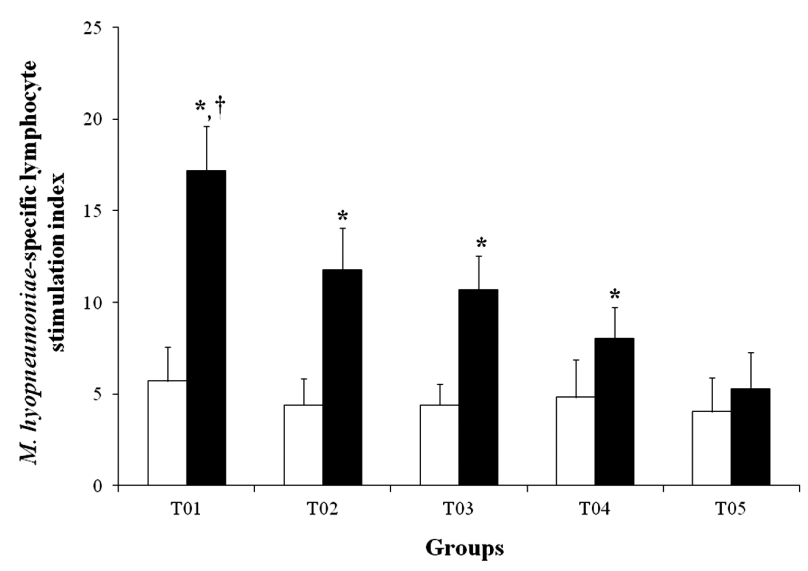

Fig. 2. Mycoplasma hyopneumoniae-specific lymphocyte stimulation index in million peripheral blood mononuclear cells (PBMCs) $/ \mathrm{m} l$ from pigs at 0 day pre-vaccination $(\square)$ and 21 days post-vaccination (ם). Variation is expressed as standard deviation; *Significant difference between 0 day pre-vaccination and 21 days post-vaccination $(P<0.05)$; $\dagger$ Significant difference among all five groups $(P<0.05)$.

pathogens were present that interfere with immune response.

Under field conditions, $M$. hyopneumoniae bacterin A was more effective in preventing and reducing the severity of lung lesions induced by $M$. hyopneumoniae than $M$. hyopneumoniae bacterin B [1]. However, this comparative study was not compared with cell-mediated immunity induced by commercial $M$. hyopneumoniae bacterins. In the present study, M. hyopneumoniae bacterin A induced higher cell-mediated immunity against $M$. hyopneumoniae than $M$. hyopneumoniae bacterin B under experimental conditions. These results suggested that the higher induction of cellmediated immunity against $M$. hyopneumoniae, the lower the severity of lung lesions induced by M. hyopneumoniae.

Vaccination is most likely to be effective, if active immunity is established before $M$. hyopneumoniae infection. Pre- 
viously, the prevalence of $M$. hyopneumoniae in lung tissue from 201 suckling piglets was $2.0 \%$, significantly lower than $9.3 \%$ in a corresponding sample from 921 nursery pigs [8]. However, the percentage of nested PCR-positive pigs, as assayed from nasal swab taken at 6 weeks of age, was dramatically increased (16\%) in the clinically infected herds [17]. Hence, the earlier the vaccination, the greater the chance of avoiding $M$. hyopenumoniae infection before vaccination.

The possible disadvantages of vaccinating piglets before weaning include the presence of maternal antibodies and an increased risk of more severe PCV2 infections after weaning [6]. M. hyopneumoniae bacterin administered in the presence of maternal antibodies exerted little to no effect on antibody response development $[3,7]$. Moreover, the timing of $M$. hyopneumoniae vaccination may be critical for minimizing the effects of vaccine-induced potentiation of PCV2-associated disease [9]. Many pig producers consequently prefer to vaccinate with single-dose $M$. hyopneumoniae bacterin at 1 week of age to minimize immunostimulation to PCV2 replication. Finally, an early single-dose vaccination of one-week-old, seronegative or seropositive pigs led to significantly fewer lung lesions than unvaccinated pigs following experimental challenge at 14 and 25 weeks later [5, 13].

IFN- $\gamma$ is a key immunoregulatory cytokine that controls the differentiation of naïve $\mathrm{CD} 4^{+} \mathrm{T}$ cells into $\mathrm{CD} 4^{+} \mathrm{Th} 1$ cells and mediates cell-mediated immunity [11]. Because $\mathrm{CD}^{+}$ Th1 cells promote a DTH response [10], the DTH response observed in only vaccinated pigs also supports a protective cellular immune response that is induced by commercial $M$. hyopneumoniae bacterins. Induction of the cell-mediated immunity by single-dose $M$. hyopneumoniae bacterins may play an important protective role, since no correlation between serum antibody level induced by humoral immunity and protection against $M$. hyopneumoniae infection has been reported $[4,16]$. On the basis of this study, the induction of $M$. hyopneumoniae-specific cell-mediated immunity by three commercial $M$. hyopneumoniae bacterins is the important protective cellular immune response leading to control of the $M$. hyopneumoniae infection in pigs.

ACKNOWLEDGMENTS. This research was supported by the Pfizer Animal Health Japan Inc. This research was also supported by contract research funds of the Research Institute for Veterinary Science (RIVS) from the College of Veterinary Medicine and by Brain Korea 21 Program for Veterinary Science in the Republic of Korea.

\section{REFERENCES}

1. Baccaro, M. R., Hirose, F., Umehara, O., Goncalves, L. C. B., Doto, D. S., Paixao, R., Shinya, L. T. and Moreno, A. M. 2006. Comparative efficacy of two single-dose bacterins in the control of Mycoplasma hyopneumoniae in swine raised under commercial conditions in Brazil. Vet. J. 172: 526-531. [Medline] [CrossRef]

2. Bandrick, M., Pieters, M., Pijoan, C. and Molitor, T. W. 2008. Passive transfer of maternal Mycoplasma hyopneumoniaespecific cellular immunity to piglets. Clin. Vaccine Immunol. 15: 540-543. [Medline] [CrossRef]

3. Dawson, A., Thevasagayam, S. J., Sherington, J., MacKinnon,
J. D., Stipkovits, L. P. and Peters, A. R. 2002. The duration of immunity after vaccination with a single dose Mycoplasma hyopneumoniae vaccine and the effect of serological status on lung lesion scores. Pig J. 50: 83-92.

4. Djordjevic, S. P., Eamens, G. J., Romalis, L. F., Nicholls, P. J., Taylor, V. and Chin, J. 1997. Serum and mucosal antibody responses and protection in pigs vaccinated against Mycoplasma hyopneumoniae with vaccines containing a denatured membrane antigen pool and adjuvant. Aust. Vet. J. 75: 504-511. [Medline] [CrossRef]

5. Jolie, R., Sabbadini, L., St. Aubin, L., Runnels, P. and Scheidt, A. 2004. Evaluation of a 25-week duration of immunity of Respisure One in Mycoplasma hyopneumoniae serological and seropositive pigs. p. 295. In: Proceedings of 18th Int. Pig Vet. Soc. Cong., Hamburg, Germany.

6. Maes, D., Segales, J., Meyns, T., Sibila, M., Pieters, M. and Haesebrouck, F. 2008. Control of Mycoplasma hyopneumoniae infection in pigs. Vet. Microbiol. 126: 297-309. [Medline] [CrossRef]

7. Martelli, P., Terreni, M., Guazzetti, S. and Cavirani, S. 2006. Antibody response to Mycoplasma hyopneumoniae infection in vaccinated pigs with or without maternal antibodies induced by sow vaccination. J. Vet. Med. B Infect. Dis. Vet. Public Health 53: 229-233. [Medline] [CrossRef]

8. Nathues, H., Kubiak, R., Tegeler, R. and Beilage, E. G. 2010. Occurrence of Mycoplasma hyopneumoniae infections in suckling and nursery pigs in a region of high pig density. Vet. Rec. 166: 194-198. [Medline] [CrossRef]

9. Opriessnig, T., Halbur, P. G., Yu, S., Thacker, E. L., Fenaux, M. and Meng, X. J. 2006. Effects of the timing of the administration of Mycoplasma hyopneumoniae bacterin on the development of lesions associated with porcine circovirus type 2. Vet. Rec. 158: 149-154. [Medline] [CrossRef]

10. Sanders, V. M. 2006. Epigenetic regulation of Th1 and Th2 cell development. Brain Behav. Immun. 20: 317-324. [Medline] [CrossRef]

11. Schroder, K., Hertzog, P. J., Ravasi, T. and Hume, D. A. 2004. Interferon- $\gamma$ : an overview of signals, mechanisms and functions. J. Leukoc. Biol. 75: 163-189. [Medline] [CrossRef]

12. Sizemore, R. C., Kern, C. H., Gottlieb, M. S. and Gottlieb, A. A. 1995. A novel methodology for quantitating the enhancement of cutaneous delayed-type hypersensitivity by IMREG-1: a measure of the immunopotentiation of cell-mediated immunity. Clin. Immunol. Immunopathol. 76: 308-313. [Medline] [CrossRef]

13. Thacker, B., Wegner, M., Erlandson, K., Maxwell, K., Thompson, J. and Thacker, E. 2002. Influence of maternal immunity on mycoplasma vaccine Respisure One efficacy. p. 482. In: Proceedings of 17th Int. Pig Vet. Soc. Cong., Iowa, U.S.A.

14. Thacker, E. 2006. Mycoplasmal diseases. pp. 701-717. In: Diseases of Swine, 9th ed. (Straw, B. E., Zimmerman, J. J., D’Allaire, S. and Taylor, D. J. eds.), Blackwell Publishing, West Sussex.

15. Thacker, E. L., Thacker, B. J., Boettcher, T. B. and Jayappa, H. 1998. Comparison of antibody production, lymphocyte stimulation and protection induced by four commercial Mycoplasma hyopneumoniae bacterins. J. Swine Health Prod. 6: 107-112.

16. Thacker, E. L., Thacker, B. J., Kuhn, M., Hawkins, P. A. and Waters, W. R. 2000. Evaluation of local and systemic immune responses induced by intramuscular injection of a Mycoplasma hyopneumoniae bacterin to pigs. Am. J. Vet. Res. 61: 1384-1389. [Medline] [CrossRef]

17. Vicca, J., Maes, D., Thermote, L., Peeters, J., Haesebrouck, F. and de Kruif, A. 2002. Patterns of Mycoplasma hyopneumoniae infections in Belgian farrow-to-finish pig herds with diverging disease-course. J. Vet. Med. B Infect. Dis. Vet. Public Health 49: 349-353. [Medline] [CrossRef] 